ISSN: $2594-4827$

\title{
A COLABORAÇÃO DA POLÍTICA DE ASSISTÊNCIA ESTUDANTIL NA PERSPECTIVA DO ENSINO MÉDIO INTEGRADO COMO TRAVESSIA RUMO À FORMAÇÃO HUMANA INTEGRAL
}

\author{
Adriano dos Santos Moraes ${ }^{1}$ \\ Alessandro Franco Melo \\ Carlos Alex Cantuária Cypriano ${ }^{3}$ \\ Jéssica Silva Almeida ${ }^{4}$ \\ Jocelma Almeida Rios ${ }^{5}$ \\ Maria da Conceição Silva Almeida ${ }^{6}$
}

Recebido em: abril/2019

Publicado em: dezembro/2019

\section{RESUMO}

Este artigo analisa a Resolução nº 01, de 29 de janeiro de 2019, que instituiu a Política da Assistência Estudantil (PAE) do Instituto Federal Baiano (IF Baiano). A pesquisa objetiva investigar em que medida a Política de Assistência Estudantil e Permanência colabora com o ensino médio integrado para travessia rumo à formação humana integral. Parte-se do pressuposto de que o objetivo a ser alcançado, na perspectiva de uma sociedade justa e igualitária, é a formação humana integral ou omnilateral. A questão epicentral da pesquisa tem que ver com a possibilidade de caminhar em direção à formação integral em uma sociedade capitalista e periférica como a brasileira. Do ponto de vista teórico, a pesquisa situa-se na visão de Moura (2013), sendo também lastreada na visão de autores como Lucília Machado, Gaudêncio Frigotto, Acácia Kuenzer, Paolo Nosella, Dermeval Saviani, José Claudinei Lombardi, entre outros, onde, a partir deste referencial teórico analisa-se a possibilidade do ensino médio integrado se constituir em uma travessia na direção pretendida e contar com a colaboração da Política de Assistência Estudantil (PAE) neste processo. Para que os objetivos propostos fossem alcançados, utilizou-se uma abordagem qualitativa e os procedimentos técnicos utilizados foram a pesquisa bibliográfica e documental. Ademais, registra-se que a pesquisa se limitou ao âmbito do Curso Técnico de Nível Médio Integrado em Agropecuária, do Instituto Federal de Educação, Ciência e Tecnologia Baiano - IF Baiano, Campus Senhor do Bonfim, em razão de ser este o único curso técnico de nível médio integrado ofertado pelo Campus Senhor do Bonfim, e esclarecemos que esta pesquisa apresentou limitações quanto ao perfil socioeconômico dos discentes beneficiários da Política de Assistência Estudantil (PAE) do IF Baiano; estrutura, composição e competências dos órgãos e colegiados da PAE do IF Baiano; e quanto à atuação da Comissão Local

\footnotetext{
${ }^{1}$ Instituto Federal Baiano. E-mail: adriano.moraes@ifbaiano.edu.br

${ }^{2}$ Instituto Federal Baiano E-mail: alessandromelo@ hotmail.com

${ }^{3}$ Instituto Federal da Bahia E-mail: alexcypriano2@ gmail.com

${ }^{4}$ Instituto Federal Baiano E-mail: jessica.almeida @ifbaiano.edu.br

${ }^{5}$ Instituto Federal da Bahia E-mail: jocelma.almeida@ifba.edu.br

${ }^{6}$ Instituto Federal da Bahia E-mail: mcalmeida@uneb.edu.br
} 
de Assistência Estudantil do IF Baiano, Campus Senhor do Bonfim, havendo, portanto, a necessidade de aprofundamento da pesquisa em trabalhos subsequentes.

Palavras-chave: Ensino Médio Técnico Integrado. Formação Humana Integral. Política de Assistência e Permanência Estudantil.

\title{
COLLABORATION OF STUDENT ASSISTANCE POLICY IN THE PERSPECTIVE OF INTEGRATED HIGH SCHOOL AS A CROSS-CUT TO HUMAN INTEGRAL TRAINING ABSTRACT
}

\begin{abstract}
This article analyzes the Resolution of the Superior Council of IF Baiano $n^{\circ} 64$ of November 30, 2016, which instituted the Student Assistance Policy under IF Baiano. The research aims to investigate to what extent the Student Assistance and Permanence Policy collaborates with the integrated high school for crossing towards the integral human formation. It is assumed that the goal to be achieved, from the perspective of a just and egalitarian society, is integral or omnilateral human formation. The epicentral question of research has to do with the possibility of moving towards integral formation in a capitalist and peripheral society such as Brazil. From the theoretical point of view, the research is based on the view of Moura (2013), and is also based on the view of authors such as Lucilia Machado, Gaudencio Frigotto, Acacia Kuenzer, Paolo Nosella, Dermeval Saviani, José Claudinei Lombardi, among others, where, based on this theoretical framework, we analyze the possibility of integrated high school becoming a crossing in the intended direction and counting on the collaboration of the Student Assistance Policy (PAE) in this process. In order to achieve the proposed objectives, a qualitative approach was used and the technical procedures used were bibliographic and documentary research. Furthermore, it is noted that the research was limited to the scope of the Technical Course of Integrated Medium Level in Agriculture, of the Federal Institute of Education, Science and Technology of Bahia - IF Baiano, Campus Senhor do Bonfim, because this is the only technical course. integrated high school level offered by the Senhor do Bonfim Campus, and we clarify that this research had limitations as to the socioeconomic profile of the students benefiting from the IF Baiano Student Assistance Policy (PAE); structure, composition and competencies of IF Baiano PAE bodies and collegiate bodies; and regarding the performance of IF Baiano's Local Student Assistance Commission, Campus Senhor do Bonfim, therefore, there is a need for further research in subsequent works.
\end{abstract}

Keywords: Integrated Technical High School. Integral Human Formation. Student Assistance and Stay Policy.

\section{INTRODUÇÃO}

A Constituição da República Federativa do Brasil (CRFB) no seu artigo $6^{\circ}$ prevê a educação como direito social e, no seu artigo 205, estabelece que a educação: 
[...] direito de todos e dever do Estado e da família, será promovida e incentivada com a colaboração da sociedade, visando ao pleno desenvolvimento da pessoa, seu preparo para o exercício da cidadania e sua qualificação para o trabalho.

A Lei de Diretrizes e Bases da Educação (LDB) - Lei 9.394, de 20 de dezembro de 1996, em seu artigo 21, discorre que a educação escolar é composta pela educação básica - formada pela educação infantil, ensino fundamental e ensino médio - e a educação superior (BRASIL, 1996).

Já no seu inciso I do artigo $3^{\circ}$, a LDB prevê que o ensino será ministrado com base no princípio da "igualdade de condições para o acesso e permanência na escola" (BRASIL, 1996).

No entanto, o que se observa, de fato, é uma flagrante disparidade neste cenário, pois nas palavras de Gaioso (2005, p. 36):

A educação é mediadora de direitos sociais e imprescindível enquanto fator de desenvolvimento humano, cultural e de acesso à cidadania, entretanto, o número de estudantes que evadem do sistema de ensino é substancial e, entre as prováveis causas, encontram-se os fatores de ordem socioeconômica.

Ademais, se por um lado a educação básica é vista como um direito universal, por outro lado, ainda persistem as dificuldades de acesso e de permanência na escola, pois se perpetuam os problemas oriundos da desigualdade de acesso, conforme os fatores econômico, social, cultural e outros.

Mesmo no caso de instituições públicas nas quais o ensino é gratuito, para que o estudante possa realmente se dedicar aos estudos e usufruir plenamente das diversas possibilidades que a convivência no ambiente escolar deve lhe proporcionar, é fundamental que o estudante possua condições mínimas para a sua sobrevivência, a exemplo de moradia, alimentação e transporte.

É justamente no sentido de intervir nessa realidade que surge a política de assistência estudantil com a finalidade de instrumentalizar os estudantes com recursos básicos e viabilizar as condições que possibilitem seu êxito acadêmico, abrangendo a demanda das camadas de baixa renda que ingressam na educação básica, através do financiamento de despesas e do atendimento das necessidades estudantis no decorrer da sua formação.

Para Kowalski (2012, p. 41) e Ramalho (2013, p. 98), a assistência estudantil é a organização de serviços de apoio ou iniciativas voltadas para o discente em situação de vulnerabilidade socioeconômica, que busquem democratizar o acesso ao ensino assegurando as condições estruturantes para favorecer a permanência e sucesso acadêmico do estudante.

Assim, as políticas de assistência estudantil compreendem ações que objetivam a superação das desigualdades de acesso, permanência e êxito do aluno, por meio de programas de benefícios sociais e de acompanhamento, com vistas a contribuir para a educação e formação humana do estudante. 
Nesse contexto, o conceito de "formação integrada" é de grande importância para a reflexão em torno da educação e formação do sujeito estudante.

Ciavatta (2005, p. 92), ao se propor a refletir sobre o que é ou que pode vir a ser a formação integrada pergunta-se: que é integrar? A autora remete o termo, então, ao seu sentido de completude, de compreensão das partes no seu todo ou da unidade no diverso, o que implica tratar a educação como uma totalidade social, isto é, nas múltiplas mediações históricas que concretizam os processos educativos.

No caso da formação integrada ou do ensino médio integrado ao ensino técnico, o que se quer com a concepção de educação integrada é que a educação geral se torne parte inseparável da educação profissional em todos os campos onde se dá a preparação para o trabalho: seja nos processos produtivos, seja nos processos educativos como a formação inicial, como o ensino técnico, tecnológico ou superior.

Significa que deve-se buscar enfocar o trabalho como princípio educativo, no sentido de superar a dicotomia trabalho manual / trabalho intelectual, de incorporar a dimensão intelectual ao trabalho produtivo, de formar trabalhadores capazes de atuar como dirigentes e cidadãos. Ou seja:

A ideia de formação integrada sugere superar o ser humano dividido historicamente pela divisão social do trabalho entre a ação de executar e a ação de pensar, dirigir ou planejar. Trata-se de superar a redução da preparação para o trabalho ao seu aspecto operacional, simplificado, escoimado dos conhecimentos que estão na sua gênese científico-tecnológica e na sua apropriação histórico-social. Como formação humana, o que se busca é garantir ao adolescente, ao jovem e ao adulto trabalhador o direito a uma formação completa para a leitura do mundo e para a atuação como cidadão pertencente a um país, integrado dignamente à sua sociedade política. Formação que, nesse sentido, supõe a compreensão das relações sociais subjacentes a todos os fenômenos. (CIAVATTA, 2005, p. 85)

Para isso, segundo Ramos (2005, p. 11) é preciso partir de alguns pressupostos, sendo o primeiro deles a necessidade de compreender que homens e mulheres são seres histórico-sociais que atuam no mundo concreto para satisfazer suas necessidades subjetivas e sociais e, nessa ação, produzem conhecimentos, por isso, o trabalho é mediação ontológica e histórica na produção de conhecimento.

O segundo pressuposto é que a realidade concreta é uma totalidade, síntese de múltiplas relações, referindo-se essa totalidade a um todo estruturado e dialético, do qual ou no qual um fato ou conjunto de fatos pode ser racionalmente compreendido pela determinação das relações que os constituem (KOSIK, 1978, p. 01).

Compreender a relação indissociável entre trabalho, ciência, tecnologia e cultura significa compreender o trabalho como princípio educativo, o que não significa "aprender fazendo", nem é sinônimo de formar para o exercício do trabalho, mas antes, equivale dizer que o ser humano é produtor de sua realidade e, por isso, se apropria dela e pode transformá-la. 
Equivale dizer, ainda, que nós somos sujeitos de nossa história e de nossa realidade. Em síntese, que o trabalho é a primeira mediação entre o homem e a realidade material e social.

O trabalho também se constitui como prática econômica, obviamente porque nós garantimos nossa existência, produzindo riquezas e satisfazendo necessidades, mas sob a perspectiva da integração entre trabalho, ciência e cultura, a profissionalização se opõe à simples a formação para o mercado de trabalho. Antes, ela incorpora valores éticos-políticos e conteúdos históricos e científicos que caracterizam a práxis humana.

Portanto, formar profissionalmente não é preparar exclusivamente para o exercício do trabalho, mas é proporcionar a compreensão das dinâmicas sócio-produtiva das sociedades modernas, com as suas conquistas e os seus revezes, e também habilitar as pessoas para o exercício autônomo e crítico de profissões, sem nunca se esgotar a elas.

No ensino médio, além do sentido ontológico do trabalho, toma especial importância seu sentido histórico, posto que é nessa etapa da educação básica que se explicita mais claramente o modo como o saber se relaciona com o processo de trabalho, convertendo-se em força produtiva, ou seja:

Ressalta-se, nesse caso, o trabalho também como categoria econômica, a partir do
qual se justificam projetos que incorporem a formação específica para o trabalho. Na
base da construção de um projeto unitário de ensino médio que, enquanto reconhece
e valoriza o diverso, supera a dualidade histórica entre formação básica e formação
profissional, está a compreensão do trabalho no seu duplo sentido; f) ontológico,
como práxis humana e, então, como a forma pela qual o homem produz sua própria
existência na relação com a natureza e com os outros homens e, assim, produz
conhecimentos; g) histórico, que no sistema capitalista se transforma em trabalho
assalariado ou fator econômico, forma específica da produção da existência humana
sob o capitalismo; portanto, como categoria econômica e práxis produtiva que,
baseadas em ex conhecimentos existentes, produzem novos
conhecimentos. (SAVIANI, 1987, p. 38)

$\mathrm{Na}$ organização do ensino médio, superando-se a disputa com a educação profissional, mas integrando-se seus objetivos e métodos em um projeto unitário, ao mesmo tempo em que o trabalho se configura como princípio educativo - condensando em si as concepções de ciência e cultura -, também se constitui como contexto econômico (o mundo do trabalho), que justifica a formação específica para atividades diretamente produtivas.

Nisso se assenta a integração entre ensino médio e educação profissional, garantindo-se uma base unitária de formação geral, com vistas a gerar possibilidades de formações específicas, mas também as de construções intelectuais elevadas; a apropriação de conceitos necessários para a intervenção consciente na realidade e a compreensão do processo histórico de construção do conhecimento.

Nesse contexto, como Moura (2013, p. 709) e outros autores, percebemos o ensino médio integrado enquanto uma possibilidade de travessia em direção à formação humana integral e nos 
propomos a investigar nesta pesquisa a colaboração da Política de Assistência Estudantil (PAE) neste processo.

A questão central da pesquisa tem que ver com a possibilidade de caminhar em direção à formação integral em uma sociedade capitalista e periférica como a brasileira e contar com o ensino médio integrado como travessia, considerando a colaboração da PAE neste feito.

Ademais, especialmente nos dias atuais de contingenciamentos e/ou cortes na área da Educação perpetrados pelo Ministério da Educação, vemos que as informações apresentadas nesta pesquisa poderão servir, em certa medida, de subsídio para os processos de planejamento, organização, gestão, tomada de decisões, avaliação e controle e monitoramento da PAE, visando a sua continuidade e implementação, a partir das percepções dos estudantes beneficiários e sujeitos envolvidos na sua execução e gestão, no âmbito do Curso Técnico de Nível Médio Integrado em Agropecuária do IF Baiano, Campus Senhor do Bonfim.

\section{ENSINO MÉDIO INTEGRADO COMO POSSIBILIDADE DE TRAVESSIA RUMO À FORMAÇÃO HUMANA INTEGRAL}

A educação é um processo permanente, iniciado com o nascimento com vida, quando passamos a ser sujeito de direito, cabendo à família e ao Estado o dever de promovê-la e incentivá-la com vistas à realização da tríplice função estabelecida na Constituição da República Federativa do Brasil CRFB, a saber: o pleno desenvolvimento da pessoa, seu preparo para o exercício da cidadania e sua qualificação para o trabalho, conforme o artigo 205 da Carta Magna.

A CRFB também prevê no seu artigo $6^{\circ}$ a educação como direito social $\mathrm{e}$, alinhada à Carta Magna, a Lei de Diretrizes e Bases da Educação - LDB (Lei 9.394 de 20 de dezembro de 1996) em seu artigo 21, discorre que a educação escolar compreende a educação básica - formada pela educação infantil, ensino fundamental e ensino médio - e educação superior (BRASIL, 1996).

No contexto da educação básica de nível médio, na visão de Moura (2013), temos o ensino médio integrado à educação profissional técnica de nível médio compreendido como uma possibilidade de travessia em direção à formação integral, ao que se afirma o seguinte:

A realidade socioeconômica brasileira exige, do ponto de vista teórico e éticopolítico, conceber e materializar um tipo de ensino médio que garanta uma base unitária para todos, fundamentado na concepção de formação humana integral, tendo como eixos estruturantes o trabalho, a ciência, a tecnologia e a cultura. Garantida essa mesma base, é preciso também que o ensino médio integrado à educação profissional técnica de nível médio seja colocado como uma possibilidade de formação. 
Neste contexto, temos que a "formação humana integral" é conceituada como formação omnilateral, sendo que, quanto ao termo "omnilateralidade", cunhado pelo filósofo e sociólogo socialista Karl Marx, na visão de Nosella (2007, p. 143), referir-se-ia, antes de tudo, a superação da dicotomia entre o trabalho produtor de mercadorias e o trabalho intelectual, pois sua proposta educacional consiste, em síntese, na fórmula pedagógico-escolar de instrução intelectual, física e tecnológica para todos, tratando-se de educação pública, gratuita e de qualidade. Nesse sentido, afirma o citado autor, a expressão "omnilateral" seria feliz, porque conota o conjunto.

Para apresentar a concepção marxiana de formação humana, recorremos a Lombardi (2010, p. 52), que, a partir do próprio Marx e de Engels leciona:

A concepção educacional marxiana/engelsiana tinha como ponto de partida a crítica da sociedade burguesa, a proclamação da necessária superação dessa mesma sociedade e como ponto de chegada a constituição do reino da liberdade. [...] a educação estará a serviço do homem e, rearticulando o trabalho manual e a atividade intelectual, deverá voltar-se plenamente à formação integral do homem.

Para Machado (1989, p. 126), na concepção de Marx, o ensino politécnico, de preparação multifacética do homem, seria o único capaz de dar conta do movimento dialético de continuidaderuptura, pois não somente estaria articulado com a tendência histórica de desenvolvimento da sociedade, como a fortaleceria. O ensino politécnico seria, por isso, fermento da transformação: contribuiria para aumentar a produção, fortalecer o desenvolvimento das forças produtivas e intensificar a contradição principal do capitalismo (entre socialização crescente da produção e mecanismos privados da apropriação).

Segundo a autora, o ensino politécnico, ao mesmo tempo em que atua diretamente sobre os indivíduos, contribui para o desenvolvimento de condições objetivas de transformação da sociedade.

Kuenzer (2002, p. 87) sinaliza na direção de que a politecnia no contexto da formação dos trabalhadores é também e fundamentalmente uma questão de natureza epistemológica, posto que a politecnia supõe uma nova forma de integração de vários conhecimentos, "que quebra os bloqueios artificiais que transformam as disciplinas em compartimentos específicos, expressão da fragmentação da ciência $[\ldots] ”$.

Nessa concepção, evidencia-se que conhecer a totalidade não é dominar todos os fatos, mas as relações entre eles, sempre reconstruídas no movimento da história. Nesta linha, em diálogo com Saviani, mas não apenas com ele, Nosella (2007, p. 137) assim se posiciona:

É importante reafirmar que Marx, como todos os clássicos, é um mestre de método, não de doutrina e, menos ainda, de linguagem. Sua proposta educacional consiste na fórmula pedagógico-escolar de "instrução intelectual, física e tecnológica para todos [...] pública e gratuita [...] de união do ensino com a produção [...] livre de interferências políticas e ideológicas" (Marx apud Manacorda, 2006a). A fórmula 
marxiana não permite privilegiar um ou outro elemento. Nesse sentido, a expressão "onilateral" é feliz, porque conota o conjunto. Mais tarde, Gramsci utiliza o termo "unitário", que acrescenta ao conjunto dos aspectos educacionais a ideia de integração. Todavia, tanto a expressão "onilateral" como "unitário" acentuam o sentido quantitativo, isto é, que abrange todos os aspectos. Se indagássemos sobre qual seria a categoria fundante e estruturante da fórmula pedagógico-escolar marxista, eu creio que deveríamos recorrer à categoria antropológica de liberdade plena para o homem, todos os homens.

Marx e Engels, ao discutirem a politecnia em seu sentido pleno, o que é compatível com o conceito de escola unitária, de Gramsci, referem-se a uma possibilidade futura a ser materializada em uma sociedade na qual a classe trabalhadora tenha ascendido ao poder político.

Evidentemente, no transcurso da luta da classe trabalhadora rumo ao domínio do poder político se produzirão, dentro do conflito entre capital e trabalho, avanços na perspectiva da superação da sociedade burguesa, inclusive de sua educação.

Neste aspecto, em contraponto a omnilateralidade há a unilateridade, que segundo Sousa Júnior (2018, p.02), se manifesta de diferentes formas: a partir da separação em classes sociais opostas, o que acaba por gerar modos diferentes de apropriação e explicação do real; revela-se por meio da especialização da formação; pela dualidade do desenvolvimento no plano intelectual ou no plano manual; e pela internalização de valores capitalistas relacionados à competitividade, ao individualismo, egoísmo e de desinteresse pela coletividade, o que pode provocar efeitos evidentes na dualidade do ensino escolar institucionalizado.

Portanto, compreender as diferenças entre o homem unilateral e omnilateral, perpassa pelas compreensões das dimensões muito maiores, pois a perspectiva unilateral trata de uma limitação do sujeito e lhe impõe aligeiramento da formação.

Neste contexto, o conceito de omnilateralidade é de grande importância para a reflexão em torno da educação e formação do sujeito, devolvendo ao homem a possibilidade de revolucionar sua postura e o seu pensamento diante do sistema capitalista, considerando a possibilidade de modificarse o quadro de desigualdades inerentes à sociedade capitalista.

Segundo Bordin (2010, p. 125):

O primeiro passo para garantir uma mudança social e evitar o retorno ao momento histórico anterior é fazer com que todo o povo esteja bem preparado intelectualmente, com uma cultura por ele formada, seja consciente dos percalços que virão e tenha sabedoria e entendimento para posicionar-se na nova maneira de conceber o mundo.

A nova concepção de mundo a que se refere Karl Marx é a de uma sociedade marcada pela ausência de classes sociais e que deve ser construída, uma vez que não se pode esperar que o atual sistema capitalista a promova. Essa construção deve ser realizada por meio de uma revolução intelectual a ser promovida agora, devolvendo ao povo a liberdade de pensamento, ao mesmo tempo 
em que lhe auxilia na organização da sua cultura, conferindo-lhe a possibilidade de criar e construir a sua própria existência no e pelo trabalho.

Desta maneira, fica evidente que se trata de uma utopia ser buscada: a de um ser humano livre, de uma sociedade menos injusta, da possibilidade de formação integrada do indivíduo e do trabalho educativo, sem a dualidade estrutural atualmente vigente no sistema capitalista.

A educação, nesse contexto, deve ser concebida como uma ferramenta capaz de transformar a realidade e conferir unidade entre a escola e a sociedade, uma vez que é impossível educar com igualdade crianças que se situam em distintas posições diante da realidade que se apresenta, tanto quanto ao acesso e permanência na escola, quanto às oportunidades reais de formação educacional, ou seja, do usufruto do direito universal à educação básica.

Neste ponto, é oportuna a explanação feita por Moura (2013, p. 713), quanto a ser o ensino médio integrado uma possibilidade ou "travessia" para a formação omnilateral:

Após revisitar a questão educacional em Marx e Engels e em Gramsci [...] defendese que a concepção educacional desses autores está pensada tendo como lócus para a sua materialização a sociedade futura (socialista) e que, dessa forma, atualmente ainda não se pode concretizar a politecnia e a escola unitária em seus sentidos plenos para todos.

Isso só será possível em uma perspectiva de futuro. Não obstante, também se conclui, a partir do pensamento desses autores, que é possível, e necessário, plantar e cuidar para que cresçam as sementes da formação humana integral, aproveitando-se das contradições do sistema capital.

Para tanto, no caminho para a travessia em direção à escola unitária, laica, politécnica, universal, pública e gratuita é necessário reclamar por escolas técnicas (teóricas e práticas), nas quais está o germe do ensino que poderá elevar a educação da classe operária bastante acima do nível das classes superior e média.

Esclarecendo uma questão conceitual, ressalta-se que o citado autor, na obra referenciada, conclui que a escola unitária vai ao encontro da formação humana integral, afirmando ser o lugar onde ela deverá ocorrer, apontando-se um vínculo entre a escola unitária e a formação politécnica, ambos em prol da formação omnilateral.

Nessa linha, concorda-se com Frigotto, Ciavatta e Ramos (2005, p. 43) quando problematizam a profissionalização no ensino médio brasileiro, e compreendem que:

Se a preparação profissional no ensino médio é uma imposição da realidade, admitir legalmente essa necessidade é um problema ético. Não obstante, se o que se persegue não é somente atender a essa necessidade, mas mudar as condições em que ela se constitui, é também uma obrigação ética e política, garantir que o ensino médio se desenvolva sobre uma base unitária para todos. Portanto, o ensino médio integrado ao ensino técnico, sob uma base unitária de formação geral, é uma condição necessária para se fazer a "travessia" para uma nova realidade (grifo dos autores). 
Após revisitarmos a questão educacional em Marx e Engels e em Gramsci, percebemos que atualmente ainda não podemos materializar a politecnia e a escola unitária em seus sentidos plenos para todos, imediatamente.

Não obstante, percebe-se que é possível e necessário plantar - e cuidar para que cresçam - as sementes da formação humana integral, politécnica, unitária, aproveitando-nos das contradições do sistema capital.

Mas, como então é possível superar as barreiras e avançar na construção teórico prática dessa perspectiva formativa? Na visão de Moura (2013, p. 51), percebe-se que:

O principal óbice é de natureza política, pois falta a decisão política do Estado brasileiro assumir a omnilateralidade como sendo a concepção norteadora da formação de todos, independentemente da origem socioeconômica, e, partir dessa referência, iniciar a travessia. Infelizmente, a falta dessa decisão é coerente com o modelo de sociedade em que se vive, pautada pelo pensamento neoliberal que considera a desigualdade social como elemento indispensável ao fortalecimento dos mercados, já que é ela que potencializa a competitividade, alimento vital do mercado. Compreende-se, portanto, que o caminho para a travessia só poderá ser construído a partir de disputas políticas em meio às contradições do sistema capital (grifo dos autores).

Neste contexto, é importante destacar o que tem sido designado como os sentidos da integração: filosófico, ético-político, epistemológico e pedagógico. O primeiro deles é de cunho filosófico e expressa a concepção de mundo, de homem, de sociedade e de educação a qual sustenta o projeto e as práticas político-pedagógicas da escola, ou seja: a concepção de Ensino Médio Integrado, assim, compreenderia o ser humano como produto das relações histórico-sociais e, nesses termos, a própria realidade.

A formação humana é o processo de reprodução dessa realidade em cada ser, de modo que ele possa apreendê -la, criticá-la e transformá-la, e segundo Ramos (2018, p. 03):

O projeto político-pedagógico visa integrar as dimensões fundamentais da práxis social, trabalho, ciência e cultura, na formação dos estudantes. Supera-se, assim, a visão da atividade econômica como estrita produção de bens e de riquezas passíveis de serem acumuladas privadamente; origem e resultado da divisão da sociedade em classes e, então, da desigualdade social. Ao contrário, a práxis econômica histórica implica na produção social necessária à existência humana, e este seria o fundamento do trabalho, o qual, na sociedade moderna, ordenou a especialização da produção, favorecendo, assim, a criação das profissões e a correlata formação. A profissionalização, sob essa perspectiva, se opõe à simples formação para o mercado de trabalho, mas incorpora valores ético-políticos e conteúdo histórico-científico os quais caracterizam a práxis humana.

Tem-se designado, como o sentido político da integração, a indissociabilidade da Educação Profissional e Básica. Esse sentido orientou a manutenção da possibilidade da Educação Profissional ser integrada, formalmente, ao Ensino Médio e segundo Ramos (2008, p. 14), esse sentido tem dois pressupostos: 
O primeiro, intrinsecamente, relacionado ao sentido filosófico, é a não admissão de que as pessoas podem se formar, tecnicamente e profissionalmente, sem apreender os fundamentos da produção moderna em todas as dimensões. Não se pode admitir, igualmente, que a estrutura educacional comporte ramos profissionalizantes desvinculados da formação básica. É preciso que a política educacional contemple a relação de requisitos entre as respectivas etapas formativas e no interior de um mesmo currículo.

Em relação aos sentidos epistemológico e pedagógico do Ensino Médio Integrado, Ramos (2008, p. 14), leciona:

Propomos a seleção integrada de conteúdos de ensino a partir da problematização dos processos produtivos em suas múltiplas dimensões: tecnológica, econômica, histórica, ambiental, social, cultural dentre outras. Isso exigirá a explicitação de teorias, de conceitos, de técnicas etc., as quais são fundamentais para a compreensão do(s) objeto(s) estudado(s) nas dimensões em que foi problematizado, localizandoo, em sequência, nos respectivos campos da ciência (áreas do conhecimento, disciplinas científicas e/ou profissionais). [...] Todavia, a fim de cumprir com o propósito de que os conteúdos sejam apreendidos como um sistema de relações, cabe identificar relações com conteúdos de campos distintos, na perspectiva da interdisciplinaridade. [...] Nesse percurso formativo, coerente com a concreticidade da vida social dos sujeitos, as contradições são tidas como relevantes e trabalhadas mediante uma análise crítica do conhecimento e da sociedade.

Desta forma, de acordo com a visão de Moura (2013, p. 707), entendemos que, na travessia rumo à formação integral, ainda é necessário reclamar por "escolas técnicas (teóricas e práticas)", com base no princípio educativo do trabalho, onde está o germe do ensino que poderá elevar a educação da classe operária bastante acima do nível das classes superior e média, sendo que, se essa tese é válida para a classe trabalhadora em geral, para o Brasil, imerso no capitalismo neoliberal como quase todo o planeta e, além disso, estando na periferia desse sistema, ela tem mais vigor ainda.

Portanto, é fundamental a busca por alternativas ao pensamento hegemônico do capital, as quais devem visar a omnilateralidade, ou seja, uma nova visão de mundo que contemple o ético, o estético e o artístico, ou seja, a formação do ser humano na sua integralidade, em todas as suas dimensões, constituindo-se a oferta de assistência estudantil no âmbito do ensino técnico de nível médio como um fator extremamente relevante deste processo, dado o panorama da Educação Profissional Técnica de Nível Médio (EPTNM) no Brasil, conforme será apresentado na seção subsequente, com base no Anuário Brasileiro da Educação Básica (2019).

\section{EDUCAÇÃO PROFISSIONAL TÉCNICA DE NÍVEL MÉDIO (EPTNM): META NO PNE, TENDÊNCIAS E RECORTES POR REGIÃo NO ANUÁRIO BRASILEIRO DA EDUCAÇ̃̃o BÁSICA}


O Anuário Brasileiro da Educação Básica foi idealizado para ser uma ferramenta de consulta para jornalistas, pesquisadores, gestores de políticas públicas e todos os que desejam compreender melhor o cenário do ensino no Brasil.

O Anuário adota como eixo estrutural o Plano Nacional de Educação (PNE) 2014- 2024, com suas 20 metas, que abrangem as várias etapas e modalidades de ensino, assim como a valorização dos professores, a gestão democrática e o financiamento do ensino público.

Conforme apresentado no Anuário, a meta da Educação Profissional Técnica de Nível Médio (EPTNM) no Plano nacional de educação (PNE) é triplicar as matrículas da Educação Profissional Técnica de nível médio, assegurando a qualidade da oferta e pelo menos $50 \%$ de expansão no segmento público.

O desenvolvimento da Educação Profissional Técnica de Nível Médio (EPTNM) é uma modalidade complementar à Educação Básica e Superior, introduzindo a possibilidade de escolha de diferentes trajetórias e expansão da jornada escolar.

A atual tendência é de crescimento da oferta na rede pública (5,7\%, de 2017 a 2018). No período de 2009 a 2018, a proporção de alunos que cursaram a EPTNM em relação ao total de matrículas na Educação Básica de Ensino Médio cresceu 6,4 pontos percentuais. Hoje, são 1,87 milhão de matrículas (sendo 1,1 milhão na rede pública).

O crescimento mais recente da EPTNM foi estimulado pelo avanço na região Nordeste, onde o aumento registrado nas matrículas totais dessa localidade foi de 7,7\% em relação a 2017. No entanto, apesar do avanço, a proporção de alunos nessa modalidade em relação ao total da Educação Básica de Nível Médio ainda é baixa no Centro-Oeste (12,1\%), se comparada ao que ocorre no Sul (22,7\%), o que exemplifica as desigualdades regionais da Educação Brasileira.

Outro aspecto importante é a forma de articulação dessa modalidade com o Ensino Médio. Atualmente, quase metade das matrículas $(47,9 \%)$ ainda acontece de forma não integrada ao currículo escolar, ou seja, de forma subsequente à última etapa da Educação Básica.

Deve-se considerar que o sistema escolar brasileiro reproduz diversas desigualdades sociais. É importante evidenciá-las para que as políticas públicas sejam colocadas em prática de forma mais equitativa. Por isso é essencial a análise de recortes por região, localidade, renda e raça/cor, sendo que 9,6\% das matrículas da Educação Básica de Nível Médio no Pará se referem à Educação Profissional Técnica. No Rio Grande do Norte, o mesmo vale para 25,8\% das matrículas e 12,1\% das matrículas da Educação Básica de Nível Médio no Centro-Oeste são da Educação Profissional Técnica de Nível Médio. No Sul, a proporção salta para 22,7\%.

Para melhor compreensão e contextualização dos dados apresentados nesta seção, apresentaremos na seção subsequente uma visão geral sobre os aspectos históricos e normativos da Assistência Estudantil no Brasil. 


\section{ASPECTOS HISTÓRICOS E NORMATIVOS DA ASSISTÊNCIA ESTUDANTIL NO BRASIL}

O histórico da Assistência Estudantil brasileira revela que a incidência de iniciativas nessa área ficava condicionada, ao contexto histórico, político e econômico do país, conforme reflexão de Garrido (2012, p. 05):

A Assistência Estudantil [...] também tem oscilado historicamente. Por vezes, as iniciativas tornam-se mais expressivas, isso porque buscam atender as pressões advindas dos movimentos sociais, notadamente do movimento estudantil. Em outros momentos as ações são mais tímidas, em decorrência da influência mais robusta dos grupos hegemônicos, no controle sobre as ações do Estado.

Da flagrante desigualdade no país, dos processos históricos de exclusão e da condição de pobreza a que milhões de brasileiros estão submetidos, decorre a dificuldade do acesso à educação por esses sujeitos, sendo necessária a criação de políticas compensatórias, como a de assistência estudantil (VIEIRA, 2013, p. xx; e ALVES, 2002, p. xx).

O Brasil possui uma tradição de apoio estudantil. As ações de assistência estudantil mais comuns - e mais antigas - de que temos notícia são, principalmente, aquelas relacionadas à oferta de alimentação e moradia, em geral disponibilizadas por meio do restaurante comunitário e casa do estudante.

Data de 1931 a primeira regulamentação que faz referência a políticas de assistência estudantil aos estudantes de ensino superior, abrangendo bolsas de estudo e serviços de assistência médica e hospitalar, de acordo com o artigo 108 do Decreto n. ${ }^{\circ} 19.851$, de 11 de abril de 1931:

Para efetivar medidas de providência e beneficência, em relação aos corpos discentes dos institutos de ensino superior, inclusive para a concessão de bolsas de estudos, deverá haver entendimento entre a Sociedade dos Professores Universitários e o Diretório Central dos Estudantes, a fim de que naquelas medidas seja obedecido rigoroso critério de justiça e de oportunidade.

Parágrafo único. A secção de previdência e de beneficência da Sociedade de Professores organizará, de acordo com o Diretório Central dos Estudantes, o serviço de assistência médica e hospitalar aos membros dos corpos discentes dos institutos de ensino superior. (BRASIL, 1931).

A primeira referência Constitucional à necessidade da assistência estudantil aparece em 1934, no artigo 157, §2 da Constituição da República dos Estados Unidos do Brasil (CREUB) de 1934, na quarta Constituição Brasileira (112 anos após a primeira). Ela estabelece que parte dos fundos de educação deveria ser aplicada em auxílios aos alunos necessitados, em forma de material escolar, bolsas de estudo, alimentação, atendimento médico e odontológico:

Art 157 - A União, os Estados e o Distrito Federal reservarão uma parte dos seus patrimônios territoriais para a formação dos respectivos fundos de educação. 
$\S 1^{\circ}$ - As sobras das dotações orçamentárias acrescidas das doações, percentagens sobre o produto de vendas de terras públicas, taxas especiais e outros recursos financeiros, constituirão, na União, nos Estados e nos Municípios, esses fundos especiais, que serão aplicados exclusivamente em obras educativas, determinadas em lei.

$\S 2^{\circ}$ - Parte dos mesmos fundos se aplicará em auxílios a aluno necessitados, mediante fornecimento gratuito de material escolar, bolsas de estudo, assistência alimentar, dentária e médica, e para vilegiaturas (BRASIL, 1934).

O novo texto Constitucional de 1937, fruto do golpe de estado, faz menção "aos mais necessitados" somente quanto à isenção da contribuição módica e mensal para caixa escolar (art. 130, CREUB/37).

Na Constituinte de 1946, na qual o enfoque dado à educação é bem diferente do anterior (CEUB/37), é dedicado um artigo à assistência estudantil, denominada assistência educacional, tornando-a obrigatória em todos os sistemas de ensino, porém sem especificar suas ações como na CREUB/34: "Art 172 - Cada sistema de ensino terá obrigatoriamente serviços de assistência educacional que assegurem aos alunos necessitados condições de eficiência escolar" (CREUB/46).

A Constituição da República Federativa do Brasil de 1967 sustenta o mesmo texto da CREUB/46, determinando que:

Art 169 - Os Estados e o Distrito Federal organizarão os seus sistemas de ensino, e, a União, os dos Territórios, assim como o sistema federal, o qual terá caráter supletivo e se estenderá a todo o País, nos estritos limites das deficiências locais. $\S 1^{\circ}$ - A União prestará assistência técnica e financeira para o desenvolvimento dos sistemas estaduais e do Distrito Federal.

$\S 2^{\circ}$ - Cada sistema de ensino terá, obrigatoriamente, serviços de assistência educacional que assegurem aos alunos necessitados condições de eficiência escolar (BRASIL, 1967).

Notamos, até aqui, que o percurso Constitucional da assistência estudantil se apresenta de maneira generalista, e somente a CREUB/34 faz destinação direta de recursos da União para auxílio aos alunos, sendo que nas Constituições posteriores, a responsabilidade é transferida para os sistemas de ensino.

Posteriormente, pela Lei de Diretrizes e Bases da Educação Nacional de 1971, foram especificadas as dimensões da assistência estudantil garantidas pela CRFB/1967:

Art. 62. Cada sistema de ensino compreenderá obrigatoriamente, além de serviços de assistência educacional que assegurem aos alunos necessitados condições de eficiência escolar entidades que congreguem professores e pais de alunos, com o objetivo de colaborar para o eficiente funcionamento dos estabelecimentos de ensino.

$\S 1$ o Os serviços de assistência educacional de que trata êste artigo destinar-se-ão, de preferência, a garantir o cumprimento da obrigatoriedade escolar e incluirão auxílios para a aquisição de material escolar, transporte, vestuário, alimentação, tratamento médico e dentário e outras formas de assistência familiar.

§ 2o O Poder Público estimulará a organização de entidades locais de assistência educacional, constituídas de pessoas de comprovada idoneidade, devotadas aos 
problemas sócio-educacionais que, em colaboração com a comunidade, possam incumbir-se da execução total ou parcial dos serviços de que trata êste artigo, assim como da adjudicação de bolsas de estudo.

Art. 63. A gratuidade da escola oficial e as bolsas de estudo oferecidas pelo Poder Público serão progressivamente substituídas, no ensino de 20 grau, pela concessão de bolsas sujeitas à restituição. Parágrafo único. A restituição de que trata êste artigo poderá fazer-se em espécie ou em serviços profissionais, na forma de que a lei determinar (BRASIL, 1971).

Por fim, o texto original da Constituição Federal publicada em 1988 previa, no artigo 208, inciso VII, o atendimento ao educando por meio de programas suplementares de material didáticoescolar, transporte, alimentação e assistência à saúde, especificamente no ensino fundamental, sendo ampliado posteriormente para educação básica (EC n 59/2009). Ademais, especifica a origem de recursos somente para os programas suplementares de alimentação e assistência à saúde previstos no artigo 208, inciso VII, financiados com recursos provenientes de contribuições sociais e outros recursos orçamentários (Art. 212, §4º , da $\mathrm{CRFB} / 88$ ).

Neste contexto, como medida que atualmente normatiza a garantia do direito constitucional apresentado no parágrafo anterior, apresentaremos na próxima seção a Resolução no 01, de 29 de janeiro de 2019, que instituiu a Política da Assistência Estudantil (PAE) do Instituto Federal Baiano (IF Baiano).

\section{NORMATIZAÇÃO DA ASSISTÊNCIA ESTUDANTIL DO INSTITUTO FEDERAL BAIANO}

A Resolução no 01, de 29 de janeiro de 2019, respaldada no Decreto 7.234, de 19 de julho de 2010 - que dispõe sobre o Programa Nacional de Assistência Estudantil (PNAES), instituiu a Política da Assistência Estudantil (PAE) do Instituto Federal Baiano (IF Baiano), que se constituindo em um conjunto de princípios e diretrizes norteadores para o desenvolvimento de programas e linhas de ações que favoreçam a democratização do acesso, permanência, e êxito do discente durante seu processo formativo, "compreendida numa perspectiva de universalização do direito à educação e formação integral dos sujeitos, abrange todos os estudantes regularmente matriculados". (IF BAIANO, 2019).

Observa-se, no $\S 2^{\circ}$ do artigo $1^{\circ}$ da Resolução n. ${ }^{\circ} 01$, de 29 de janeiro de 2019 , que a destinação de recursos financeiros através de programas e ações servirá, prioritariamente, ao atendimento das necessidades do corpo discente cuja renda familiar per capita seja de até um salário mínimo e meio vigente.

Os objetivos específicos da Política de Assistência Estudantil do IF Baiano são destacados no seu artigo $4^{\circ}$, a saber: 
I - ampliar as possibilidades para o acesso, contribuindo para a promoção da inclusão social pela educação;

II - propiciar a igualdade de oportunidades entre todos(as) os(as) estudantes matriculados(as) no IF Baiano;

III - contribuir para a melhoria do desempenho acadêmico dos(as) estudantes, a partir de medidas que busquem minimizar situações de retenção e evasão;

IV - desenvolver ações que assegurem, de forma preventiva, a assistência à saúde do (a) estudante;

$\mathrm{V}$ - implementar ações educativas que propiciem o desenvolvimento do pensamento crítico, político e criativo dos(as) estudantes;

VI - fomentar novas oportunidades de aprendizagem, permitindo que todos(as) os(as) estudantes do IF Baiano construam as habilidades socioprofissionais necessárias à sua inserção, permanência e êxito no mundo do trabalho, e/ou o prosseguimento na vida acadêmica;

VII - realizar o mapeamento da realidade socioeconômica e acadêmica dos estudantes atendidos pela política a fim de direcionar suas ações;

VIII - estimular a criação e ampliação de programas e projetos voltados à Assistência Estudantil.

IX - contribuir para aumentar a eficiência e eficácia das ações do Instituto para o cumprimento da sua missão. (IF BAIANO, 2019).

Neste ponto, destaca-se aqui, um dos programas instituídos por esta política de assistência estudantil, previsto no artigo 15, inciso I: o Programa de Assistência e Inclusão Social do Estudante - PAISE.

O PAISE é destinado aos estudantes regularmente matriculados, que possuam renda per capita de até um salário mínimo e meio vigente - conforme definido pelo Decreto 7.234, de 19 de julho de 2010, para garantia da permanência dos estudantes na instituição, durante os anos destinados ao processo formativo do curso escolhido (artigo 16).

Constituem-se benefícios do PAISE, conforme o artigo 18 da Resolução n. ${ }^{\circ} 01$, de 29 de janeiro de 2019:

I - auxílio moradia; II - auxílio alimentação; III - auxílio transporte; IV - auxílio material acadêmico; V - auxílio uniforme; VI - auxílio cópia e impressão; VII auxílio permanência; VIII - auxílio creche; IX - auxílio PROEJA. (IF BAIANO, 2019).

Os auxílios previstos não são acumulativos, exceto os auxílios material acadêmico e uniforme, e para usufruir dos auxílios do PAISE serão exigidos dos contemplados a frequência regular, ressalvados os casos justificados e sob acompanhamento pedagógico (artigos 18 e 19).

O auxílio moradia consiste na concessão de recurso financeiro, fixo e mensal aos estudantes oriundos de municípios distantes, e/ou com dificuldade de translado diário, e que não tenham sido beneficiados com a Residência Estudantil.

O auxílio alimentação consiste na concessão de repasse financeiro, de valor fixo e mensal, ao estudante para custear as despesas com alimentação durante o período letivo, preferencialmente nos Campi onde não houver refeitório. 
Já o auxílio transporte traduz-se na concessão de repasse financeiro, fixo e mensal, à estudantes para custear as despesas com transporte, auxiliando o translado de ida e volta ao Campus durante o período letivo.

O auxílio material acadêmico está relacionado com a concessão de repasse financeiro único anual ao estudante, para auxiliar nas despesas com material acadêmico, podendo o auxílio ser acumulativo com qualquer outro.

O auxílio uniforme consiste na concessão de repasse financeiro único anual ao estudante do ensino médio integrado, subsequente e PROEJA para custear as despesas com uniforme, podendo o auxílio ser acumulativo com qualquer outro.

O auxílio cópia e impressão, por óbvio, diz respeito a garantia da reprodução e/ou impressão do material de uso acadêmico durante o período letivo.

O auxílio permanência refere-se ao auxílio financeiro mensal, destinado aos estudantes que não se enquadram nos demais auxílios financeiros previstos pelo PAISE, cuja renda per capita familiar seja inferior a 50\% do salário mínimo vigente.

O Auxílio Creche visa contribuir para a redução das taxas de evasão e retenção de estudantes pais ou mães, em situação de vulnerabilidade socioeconômica, através da concessão de repasse financeiro, fixo e mensal, ao estudante com filho(a) de até 5 (cinco) anos de idade, ou com deficiência comprovada por laudo médico, que resida com o estudante e não possua amparo familiar para o cuidado durante o horário de aula.

E, o auxílio PROEJA (Programa Nacional de Integração da Educação Profissional com a Educação Básica, na Modalidade de Jovens e Adultos), consiste na concessão de repasse financeiro, fixo e mensal, aos estudantes regularmente matriculados em cursos do PROEJA Técnico ou de Formação Inicial e Continuada (FIC), em situação de vulnerabilidade social.

Por último, tem-se o auxílio eventual, consistindo na concessão de repasse financeiro ao estudante em situação de vulnerabilidade socioeconômica, caracterizado como ajuda de custo para necessidades específicas, relativas a demandas emergenciais, no qual todos os gastos com a utilização deste auxílio devem ser comprovados por meio de recibos e/ou notas fiscais.

Através da análise da Resolução CONSUP nº 64, de 30 de novembro de 2016, percebe-se que a Política de Assistência Estudantil do IF Baiano foi estruturada com vistas a dar a sua parcela de contribuição para a fruição do direito social à educação, referenciada em uma perspectiva de atendimento integral dos estudantes, contemplando aspectos sociais, acadêmicos, de saúde, culturais e de formação cidadã, o que será mais detalhado na próxima seção.

\section{A POLÍTICA DE ASSISTÊNCIA ESTUdANTIL COMO ELEMENTO COLABORADOR DA TRAVESSIA RUMO À FORMAÇÃO INTEGRAL NO CONTEXTO DO CURSO




\section{TÉCNICO DE NÍVEL MÉDIO INTEGRADO EM AGROPECUÁRIA DO IF BAIANO, CAMPUS SENHOR DO BONFIM}

A educação é concebida pela legislação como um direito fundamental e universal, além de ser um instrumento de formação do exercício da cidadania e emancipação social, devendo comprometerse com a formação integral do ser humano.

Todavia, a realidade na educação brasileira ainda é marcada pela dificuldade não só de acesso, mas também de permanência no ensino básico, pois persistem os problemas oriundos da desigualdade de acesso, os quais, em geral, estão ligados a fatores econômico, social, cultural, de gênero, dentre outros.

É justamente com a finalidade de intervir nessa realidade que surge a política de assistência estudantil, a fim de viabilizar as condições materiais que possibilitem o êxito acadêmico dos alunos, abrangendo principalmente as demandas das camadas de baixa renda que ingressam na educação básica, através do financiamento de despesas e do atendimento das necessidades básicas estudantis, no decorrer da formação do discente beneficiário.

Dessa forma, a assistência estudantil promove ações que contribuem para o acesso, a permanência e o êxito dos estudantes, com vistas à inclusão social, à produção do conhecimento e à melhoria do desempenho acadêmico e do bem-estar integral do educando.

A Assistência Estudantil, dessa forma, deve ser compreendida como uma política capaz de contribuir para a mitigação das disparidades decorrentes das distintas posições que os estudantes se encontram, notadamente em termos econômicos e sociais, visando fomentar o acesso e permanência na escola, além de incentivar a criatividade, a reflexão crítica, as atividades e os intercâmbios cultural, esportivo, artístico, político, científico e tecnológico, o que pode contribuir com o germe da formação integral.

Neste contexto, apresentamos a experiência do Curso Técnico de Nível Médio Integrado em Agropecuária, do Instituto Federal Baiano, Campus Senhor do Bonfim. Pondera-se que, em que pese ser essa experiência valiosa, esta não se constitui em um modelo completo ou perfeito quanto a contribuição da assistência estudantil à omnilateralidade, dada as condições sistémicas prevalecentes no status quo. Entretanto, nos serve de referência, de norte ou horizonte, à medida que demostra o impacto positivo da Política de Assistência Estudantil na vida dos estudantes, uma vez que viabiliza aos estudantes as condições necessárias e os meios materiais básicos para o usufruto mais proveitoso do ambiente escolar, através dos incentivos que compõe essa política.

Nesta linha, apresentamos no quadro abaixo o número de discentes matriculados no Curso Técnico de Nível Médio Integrado em Agropecuária, do Instituto Federal Baiano, Campus Senhor do Bonfim, no ano de 2018: 
Quadro 1 - Discentes matriculados no Curso Técnico de Nível Médio Integrado em Agropecuária, do Instituto Federal Baiano, Campus Senhor do Bonfim (2018).

\begin{tabular}{|c|c|c|c|c|}
\hline \multirow{2}{*}{ SÉRIES } & \multicolumn{5}{|c|}{ TURMAS } \\
\hline- & A & B & C & D \\
\hline $1^{\text {a }}$ & 40 & 41 & 40 & 41 \\
\hline $2^{\text {a }}$ & 29 & 35 & 29 & 31 \\
\hline $3^{\text {a }}$ & 25 & 23 & 25 & 26 \\
\hline TOTAL & $\mathbf{9 4}$ & $\mathbf{9 9}$ & $\mathbf{9 4}$ & $\mathbf{9 8}$ \\
\hline
\end{tabular}

Fonte: Secretaria de Registros Acadêmicos (SRA) do IF Baiano, Campus Senhor do Bonfim.

Entre os discentes matriculados no Curso Técnico de Nível Médio Integrado em Agropecuária, do Instituto Federal Baiano, Campus Senhor do Bonfim, no ano de 2018, o quantitativo de beneficiários da Política de Assistência Estudantil foi o seguinte:

Quadro 2 - Discentes beneficiários da PAE no Curso Técnico de Nível Médio Integrado em Agropecuária, do Instituto Federal Baiano, Campus Senhor do Bonfim (2018).

\begin{tabular}{|c|c|}
\hline TIPO DE AUXÍLIO & NÚMERO DE BENEFICIÁRIOS \\
\hline Auxílio moradia & 3 \\
\hline Auxílio transporte & 31 \\
\hline Auxílio cópia e impressão & 56 \\
\hline Auxílio permanência & 0 \\
\hline Auxílio alimentação & 0 \\
\hline Auxílio creche & 0 \\
\hline Auxílio eventual & 0 \\
\hline Auxílio PROEJA & $\mathbf{9 6}$ \\
\hline TOTAL & Campus Senhor do Bonfim.
\end{tabular}

Fonte: Coordenação de Apoio ao Educando (CAE) do IF Baiano, Campus Senhor do Bonfim.

Em relação aos auxílios acumulativos - material acadêmico e uniforme - o quantitativo de beneficiários da Política de Assistência Estudantil foi o seguinte: 
Quadro 3 - Discentes beneficiários de auxílios acumulativos da PAE no Curso Técnico de Nível

Médio Integrado em Agropecuária, do Instituto Federal Baiano, IF Baiano Campus Senhor do Bonfim (2018)

\begin{tabular}{|c|c|}
\hline TIPO DE AUXÍLIO & NÚMERO DE BENEFICIÁRIOS \\
\hline Auxílio material acadêmico & 35 \\
\hline Auxílio uniforme & 50 \\
\hline TOTAL & $\mathbf{8 5}$ \\
\hline
\end{tabular}

Fonte: Coordenação de Apoio ao Educando (CAE) do Campus Senhor do Bonfim.

Em face das informações advindas da presente pesquisa, é possível perceber que a Assistência Estudantil dá a sua parcela de contribuição para a formação dos discentes do Curso Técnico de Nível Médio Integrado em Agropecuária, do Instituto Federal Baiano (IF Baiano), Campus Senhor do Bonfim, uma vez que contribui para que o estudante possa se dedicar mais aos estudos e usufruir das diversas possibilidades que a convivência no ambiente escolar deve lhe proporcionar, por colocar à disposição dos alunos beneficiados pela PAE as condições materiais mínimas para a sua sobrevivência, como moradia, alimentação (através de refeições gratuitas no refeitório do próprio Campus) e transporte.

Ressalta-se aqui a importância da assistência estudantil, enquanto um dos elementos necessários ao enfrentamento e esforço de superação aos obstáculos à busca do desempenho acadêmico qualificado, da permanência e do êxito dos estudantes, na medida em que contribui para o desenvolvimento acadêmico dos alunos e até mesmo para a diminuição dos percentuais de evasão escolar.

Nesta linha de pensamento, em um estudo realizado por Viana (2016, p. 101 a 102) com discentes do ensino técnico integrado ao médio do Instituto Federal de Educação, Ciência e Tecnologia de São Paulo, campus São João da Boa Vista, verificou-se o seguinte, em relação ao programa de assistência estudantil lá implementado:

A partir deste estudo foi possível verificar a contribuição do programa para os alunos do ensino técnico integrado ao médio, ao viabilizar a materialização do direito à educação, através da democratização do ensino oriundo do acesso e da permanência. Os alunos conseguem identificar o programa como direito quando relacionam as ações deste com a viabilização de condições de igualdade, reconhecendo que há uma sociedade de classes e tamanha desigualdade social e que ter acesso ao programa não se trata de favor, mas sim de uma política social que prevê direito de cidadania.

Os estudantes envolvidos atribuem importância significativa às ações desta política e vinculam a relação do estudo como caminho para a cidadania na possibilidade de poderem ser inseridos no mundo do trabalho, mas além disso atribuíram à educação um papel de formação critica do ser humano e possibilidade de atuar, deliberar e participar de ações que envolvam interesses coletivos e que visem um relacionamento mais harmônico pautado na ética, no respeito, solidariedade e na possibilidade de desenvolver seres humanos que se façam sujeitos (grifo dos autores). 
Destacamos que, conforme também relata a citada autora, não se trata somente de acessar ou permanecer na escola, mas também de viabilizar a participação efetiva e integral dos alunos, dandolhes sentimento de pertencimento a instituição, uma vez que se faz necessária o desenvolvimento de ações que compõem a educação para além da sala de aula e para além dos interesses do capital e do mercado de trabalho.

\section{CONSIDERAÇÃOES FINAIS}

Mesmo no caso de instituições públicas, nas quais o ensino é gratuito, para que o estudante possa realmente se dedicar aos estudos e usufruir plenamente das diversas possibilidades que a convivência no ambiente escolar deve lhe proporcionar, é fundamental que disponha de condições mínimas para a sua sobrevivência, como moradia, alimentação e transporte.

Neste contexto, as políticas de assistências estudantis compreendem ações que objetivam dar a sua parcela de contribuição para o complexo desafio da superação das desigualdades de acesso, permanência e êxito do aluno, por meio de programas de benefícios sociais e de acompanhamento, com vistas a colaborar para a educação e formação humana integral do estudante.

Dessa forma, a política de assistência estudantil surge com a finalidade de incentivar os estudantes e viabilizar as condições que contribuam para o seu êxito acadêmico, abrangendo a demanda das camadas de baixa renda que ingressam na educação básica através do financiamento de despesas e do atendimento das necessidades estudantis no decorrer da sua formação.

Partindo-se do pressuposto de que o objetivo a ser alcançado, na perspectiva de uma sociedade justa e igualitária, é a formação humana integral ou omnilateral, a pesquisa desenvolvida discorreu sobre a possibilidade do ensino médio integrado se constituir em uma travessia na direção pretendida e contar com a colaboração da Política de Assistência Estudantil (PAE) neste processo e apresentou a Resolução CONSUP $n^{\circ}$ 64, de 30 de novembro de 2016 e dados referentes aos discentes beneficiários dos auxílios da PAE, matriculados no Curso Técnico de Nível Médio Integrado em Agropecuária do IF Baiano, Campus Senhor do Bonfim, no ano de 2018.

Em face das informações apresentadas na presente pesquisa, entende-se que a Assistência Estudantil dar a sua parcela de colaboração para a formação mais qualificada dos discentes do Curso Técnico de Nível Médio Integrado em Agropecuária do IF Baiano, Campus Senhor do Bonfim, na medida que ajuda a viabilizar que o estudante possa usufruir das diversas possibilidades que a convivência no ambiente escolar deve lhe proporcionar, por colocar à sua disposição as condições materiais mínimas para a sua sobrevivência, como moradia, alimentação e transporte. 
Desta forma, entendemos que a essência da política de assistência e permanência estudantil deve se materializar em um conjunto de ações programáticas voltadas à emancipação e promoção dos discentes em situação de vulnerabilidade socioeconômica, com dificuldades de acesso, permanência e conclusão nos cursos Técnicos de Nível Médio Integrado da Educação Profissional Tecnológica.

Por isso, compreendemos que, tratando-se de ensino médio integrado, a democratização do acesso escolar e a permanência na educação básica são demandas que podem ser fortalecidas através do apoio advindo de programas de auxílio estudantis, quando organizados dentro de uma Política de Assistência e Permanência Estudantil qualificada, que faça mais do que simplesmente prevê a concessão de benefícios aos estudantes, ou seja, que esteja alinhada a diretrizes, princípios e objetivos que visem a formação integral do sujeito beneficiário deste direito social.

Ademais, registra-se que a pesquisa se limitou ao âmbito do Curso Técnico de Nível Médio Integrado em Agropecuária, do Instituto Federal de Educação, Ciência e Tecnologia Baiano - IF Baiano, Campus Senhor do Bonfim, em razão de ser este o único curso técnico de nível médio integrado ofertado pelo Campus Senhor do Bonfim, e esclarecemos que esta pesquisa apresentou limitações quanto ao perfil socioeconômico dos discentes beneficiários da Política de Assistência Estudantil (PAE) do IF Baiano; estrutura, composição e competências dos órgãos e colegiados da PAE do IF Baiano; e quanto à atuação da Comissão Local de Assistência Estudantil do IF Baiano, Campus Senhor do Bonfim, havendo, portanto, a necessidade de aprofundamento da pesquisa em trabalhos subsequentes.

\section{REFERÊNCIAS}

ALVES, Jolinda de Moraes. A assistência estudantil no âmbito da política de educação superior pública. 2002.

BORDIN, João Henrique. Educação revessa. Pelotas, RGS: Editora Universitária/UFPEL, 2010.

BRASIL. Constituição da República dos Estados Unidos do Brasil de 1934. Rio de Janeiro, 1934. Disponível em: http://www.planalto.gov.br/ccivil_03/Constituicao/Constitui\%C3\%A7ao34. htm. Acesso em: 10 de out. de 2019

BRASIL. Constituição dos Estados Unidos do Brasil. Rio de Janeiro de 1937. Disponível em http://www.planalto.gov.br/ccivil_03/Constituicao/Constitui\%C3\%A7ao37.htm. Acesso em 10 out. 2019.

BRASIL. Constituição dos Estados Unidos do Brasil. Rio de Janeiro de 1946. Disponível em http://www.planalto.gov.br/ccivil_03/Constituicao/Constitui\%C3\%A7ao46.htm. Acesso em 10 out. 2019.

BRASIL. Constituição dos Estados Unidos do Brasil. Rio de Janeiro de 1967. Disponível em http://www.planalto.gov.br/ccivil_03/Constituicao/Constitui\%C3\%A7ao67.htm. Acesso em 10 out. 2019. 
BRASIL. Constituição da República Federativa do Brasil de 1988. Brasília-DF, Presidência da República. Disponível em: http://www.planalto.gov.br/ccivil_03/constituicao/constituicao compilado.htm. Acesso em: 10 out. 2019.

BRASIL. Decreto $\mathbf{n}^{0}$ 19.851, de 11 de abril de 1931. Dispõe que, o ensino superior no Brasil obedecerá, de preferência, ao sistema universitário, podendo ainda ser ministrado em institutos isolados, e que a organização técnica e administrativa das universidades é instituída no presente decreto, regendo-se os institutos isolados pelos respectivos regulamentos, observados os dispositivos do seguinte Estatuto das Universidades Brasileiras. Disponível em: https://www2.camara.leg.br/legin/fed/decret/1930-1939/decreto-19851-11-abril-1931-505837publicacaooriginal-1-pe.html. Acesso em: 05 set. 2019.

BRASIL. Decreto $\mathbf{n}^{\mathbf{0}}$ 7.234, de 19 de julho de 2010. Dispõe sobre o Programa Nacional de Assistência Estudantil - PNAES. Disponível em: http://www.planalto.gov.br/ccivil_03/_ato20072010/2010/decreto/d7234.htm. Acesso em: 05 set. 2019.

BRASIL. Emenda constitucional $n^{0} 59$, de 11 de novembro de 2009. Acrescenta $\S 3^{\circ}$ ao art. 76 do Ato das Disposições Constitucionais Transitórias para reduzir, anualmente, a partir do exercício de 2009, o percentual da Desvinculação das Receitas da União incidente sobre os recursos destinados à manutenção e desenvolvimento do ensino de que trata o art. 212 da Constituição Federal, dá nova redação aos incisos I e VII do art. 208, de forma a prever a obrigatoriedade do ensino de quatro a dezessete anos e ampliar a abrangência dos programas suplementares para todas as etapas da educação básica, e dá nova redação ao $\S 4^{\circ}$ do art. 211 e ao $\S 3^{\circ}$ do art. 212 e ao caput do art. 214, com a inserção neste dispositivo de inciso VI. Disponível em: http://www.planalto.gov.br/ccivil_03/constituicao/Emendas/Emc/emc59.htm. Acesso em: 05 set. 2019.

BRASIL. Lei $\mathbf{n}^{\circ}$ 5.692, de 11 de agosto de 1971. Fixa Diretrizes e Bases para o ensino de $1^{\circ}$ e $2^{\circ}$ graus, e dá outras providência. Disponível em: http://www.planalto.gov.br /ccivil_03/_ato20072010/2008/lei/111892.htm. Acesso em: 05 set. 2019.

BRASIL. Lei $\mathbf{n}^{0}$ 9.394, de 20 de dezembro de 1996. Estabelece as diretrizes e bases da educação nacional. Disponível em: http://www.planalto.gov.br/ccivil_03/LEIS/L9394.htm. Acesso em: 04 set. 2019.

CIAVATTA, Maria. A formação integrada: a escola e o trabalho como lugares de memória e de identidade. In: RAMOS, Marise (Org.); FRIGOTTO, Gaudêncio (Org.); CIAVATTA, Maria (Org.). Ensino Médio Integrado: Concepção e Contradições. São Paulo: Cortez, 2005, p. 83-105. Disponível em: http://periodicos.uff.br/trabalhonecessario/article/view/6122/5087. Acesso em: 04 set. 2019.

CRUZ, Priscila (Org) e MONTEIRO, Luciano (Org). Anuário Brasileiro da Educação Básica 2019. São Paulo: Editora Moderna LTDA, $2019 . \quad$ Disponível em: https://www.todospelaeducacao.org.br/_uploads/_posts/302.pdf. Acesso em: 09 de out. 2019.

FRIGOTTO, Gaudêncio; CIAVATTA, Maria; RAMOS, Marise. A gênese do decreto n. 5.154/2004: um debate no contexto controverso da democracia restrita. In: FRIGOTTO, G. et al. (Orgs.). Ensino médio integrado: concepções e contradições. São Paulo: Cortez, 2005. p. 21-56. Disponível em: $\quad$ http://forumeja.org.br/pf/sites/forumeja.org.br.pf/files/CIAVATTAFRIGOTTORA MOS.pdf.Acesso em: 06 set. 2019.

GAIOSO, Natalicia Pacheco de Lacerda. O fenômeno da evasão escolar na educação superior no Brasil. Dissertação (Mestrado em Educação) - Programa de Pós-Graduação em Educação da 
Universidade Católica de Brasília, Brasília-DF, 2005, 75 p. Disponível em: http://www.scielo.br/scielo.php?script=sci_nlinks\&ref=000127\&pid=S1414$4077201100020000700011 \& \operatorname{lng}=$ pt. Acesso em: 15 set. 2019.

GARRIDO, Edleuza Nery. Assistência Estudantil: Sua importância, atores envolvidos e panorama atual. In: Seminário Universidade Sociedade. Semana Kirimurê, p.1-17, CachoeiraBahia, 2012.

INSTITUTO FEDERAL DE EDUCAÇÃO, CIÊNCIA E TECNOLOGIA BAIANO. Política de Assistência Estudantil. Resolução n. ${ }^{\circ}$ 01, de 29 de janeiro de 2019. Disponível em: http://www.ifbaiano.edu.br/unidades/itapetinga/files/2011/05/Resolucao-01-2019-AprovaPol\%C3\%ADtica-de-Assist\%C3\%AAncia-Estudantil-Processo-n\%C2\%BA-23327.0025302018.42.pdf. Acesso em: 01 de abril 2019.

KOSIK, Karel. Dialética do Concreto. p.01. Petrópolis: Vozes, 1978.

KOWALSKI, A. V.. Os (des)caminhos da política de assistência estudantil e o desafio na garantia de direitos. Tese (Doutorado em Serviço Social) - Pontifícia Universidade Católica do Rio Grande do Sul, Porto Alegre, 2012, 179 p. Disponível em: http://repositorio.pucrs.br/dspace/handle/10923/5137. Acesso em: 14 out. 2019.

KUENZER, Acácia Zeneida. (Org.). Ensino médio: construindo uma proposta para os que vivem do trabalho. 3. ed. São Paulo: Cortez, 2002. Disponível em: https://pt.slideshare.net/familiaestagio/ensino-mdio-uma-proposta-para-os-que-vivem-do-trabalho. Acesso em: 14 out. 2019.

LOMBARDI, José Claudinei. Reflexões sobre educação e ensino na obra de Marx e Engels. Tese (Livre-docência) - Faculdade de Educação, Universidade Estadual de Campinas, Campinas-SP, 2010, 377p. Disponível em: https://www.google.com/url?sa=t\&rct=j\&q=\&esrc=s\&source=web $\& c d=1 \& v e d=2$ ahUKEwjcreCAiqflAhXGiFwKHXnpAsoQFjAAegQIABAC \&url=http\%3A\%2F\%2 Fwww.bibliotecadigital.unicamp.br\%2Fdocument\%2F\%3Fdown\%3D40989\&usg=AOvVaw35XKk NyjwqMoZyqiNpZUDb. Acesso em: 14 out. 2019.

MACHADO, Lucília. Politecnia, escola unitária e trabalho. São Paulo: Cortez, 1989. Disponível em: $\quad$ http://livrozilla.com/doc/1356987/politecnia--escola-unit\%C3\%A1ria-e-trabalho-li\%C3\%A7\%C3\%B5es-do-passado. Acesso em: 14 out. 2019.

MOURA, Dante Henrique. Ensino médio integrado: subsunção aos interesses do capital ou travessia para a formação humana integral?. Educ. Pesquisa, São Paulo, v. 39, n. 3, p. 705-720, jul./set. 2013. Disponível em: http://www.scielo.br/pdf/ep/v39n3/10.pdf. Acessado em: 03 de janeiro de 2019.

NOSELLA, Paolo. Trabalho e perspectivas de formação dos trabalhadores: para além da formação politécnica. Rev. Bras. Educ., Rio de Janeiro , v. 12, n. 34, p. 137-151, Abr. 2007 . Disponível em: http://www.scielo.br/scielo.php?script=sci_arttext\&pid=S141324782007000100011\&lng=en\&nrm=iso. Acesso em: 09 out. 2019.

RAMALHO, Ludmila Eleonora Gomes. Abordagem avaliativa da política de assistência estudantil em uma instituição de ensino profissional. Dissertação (Mestrado Profissional em Gestão e Avaliação da Educação Pública) - Universidade Federal de Juiz de Fora, Juiz de Fora-MG, 2013, 164p. Disponível em: https://repositorio.ufjf.br/jspui/bitstream/ufjf/1052/1/ludmilaeleonorago mesramalho.pdf. Acesso em: 12 set. 2019. 
RAMOS, Marise Nogueira (Orgs.). Ensino médio integrado: concepção e contradições. São Paulo: Cortez, 2005. Disponível em: https://tecnicadmiwj.files.wordpress.com/2008/09/texto-concepcaodo-ensino-medio-integrado-marise-ramos1.pdf. Acesso em: 15 set. 2019.

RAMOS, Marise Nogueira. Ensino médio integrado: lutas históricas e resistências em tempos de regressão. In: Anais do II Seminário Nacional do Ensino Médio Integrado, IFB, Brasília-DF, 2008, 14p. Disponível em: https//www.even3.com.br/anais/snemi/57589-ENSINO-MEDIOINTEGRADO--LUTAS-HISTORICAS-E-RESISTENCIAS-EM-TEMPOS-DE-REGRESSAO.

Acesso em: 19 set. 2019.

RAMOS, Marise Nogueira. O projeto unitário de ensino médio sob os princípios do trabalho, da ciência e da cultura. In: Frigotto, G.; Ciavatta, M. (Orgs.). Ensino médio: ciência, cultura e trabalho. Brasília: Ministério da Educação, 2004. p. 37-52. Disponível em: https://www.google.com/url?sa=t\&rct=j\&q=\&esrc=s\&source=web\&cd=1\&ved=2ahUKEwjwiYT Wj6flAhX8ILkGHW1ADFoQFjAAegQIBRAC\&url=https\%3A\%2F\%2Fservicos.educacao.rs.gov. br\%2Fpse\%2Fbinary\%2Fdown_sem\%2FDownloadServlet\%3Farquivo\%3Dtextos\%2FTextoensino-medio-livro.pdf\&usg=AOvVaw0UD4HJ-tBEsipcYWsl1dJG. Acesso em: 15 set. 2019.

RAMOS, Marise Nogueira. Possibilidades e desafios na organização do currículo integrado. In: RAMOS, Marise. (Org.); FRIGOTTO, Gaudêncio (Org.) ; CIAVATTA, Maria (Org.) . Ensino Médio Integrado: Concepção e ontradições. São Paulo: Cortez, 2005; pp. 106-127.

SAVIANI, Demerval. Escola e Democracia. São Paulo: Cortez/Autores Associados, 1987, 90 p. Disponível em: https://www5.unioeste.br/portalunioeste/arquivos/phc/D_Saviani_Escola_e_ democracia.pdf. Acesso em: 12 set. 2019.

SOUSA JUNIOR, Justino de. Omnilateralidade. $\mathrm{p}$ 02-05. Disponível em: http://www.sites.epsjv.fiocruz.br/dicionario/verbetes/omn.html\#topo. Acessado em: 04 de janeiro de 2019.

VIEIRA, Joselya Claudino de Araújo. Política de cotas nas universidades federais e assistência estudantil: desafios para democratização da Educação Superior no Brasil. Jornada Internacional de Políticas Públicas, nº 6. Anais. São Luiz: UFMA, 2013. 